\title{
ANALYSIS OF INDICATIONS AND COMPLICATIONS OF ELECTIVE CAESAREAN SECTION IN PRIMI AT A TERTIARY CARE CENTRE, VIJAYAWADA, ANDHRA PRADESH, INDIA
}

\author{
Potharaju Jayanthi', Ganti Ratna²
}

${ }_{1}^{1}$ Associate Professor, Department of Obstetrics and Gynaecology, Siddhartha Medical College, Vijayawada.

${ }^{2}$ Associate Professor, Department of Obstetrics and Gynaecology, Siddhartha Medical College, Vijayawada.

\begin{abstract}
BACKGROUND
ABSTRACT

Most common operation performed in any obstetric institute is caesarean section. Worldwide, there is increasing rate of caesarean section. Most important indication is repeat caesarean section. Hence, unless we reduce the primary caesarean section rate, we cannot control the total caesarean section rate.

The aim of the present study was to analyse critically the indications and complications of elective caesarean section performed on primigravida and pregnancy with previous miscarriages in a tertiary care centre.
\end{abstract}

\section{MATERIALS AND METHODS}

This is a prospective descriptive study conducted in Government General Hospital, Vijayawada. All cases of primary elective caesarean sections performed on primigravida or pregnancy with previous miscarriages who reached the period of viability for first time in the present pregnancy were taken up for present study. The present study was conducted in Government General Hospital, Vijayawada, Andhra Pradesh from the month of April 2017 to September 2017, that is for 6 months. All cases of primary elective caesarean sections were analysed for the indication of surgery and postoperative complications. Maternal and perinatal outcome was noted. All patients were followed till discharge.

\section{RESULTS}

Present study comprised of $210(n=210)$ pregnant women who underwent primary elective caesarean section in primigravida and pregnancy with previous abortions. Indications and complications of primary elective caesarean section were analysed. Indications for caesarean sections were liberalised in present days. Operation is being performed for more of foetal indications in view of improved neonatal facilities. Present study analysis showed that $18.7 \%$ of sections in Breech 9.5\%, 7\% in CPD, short primi $7.6 \%$, preeclampsia $11.9 \%$, oligohydramnios $28.1 \%$, long marital life $2.3 \%$, IUGR $3.3 \%$, placenta previa $0.4 \%$ and others remaining. The analysis showed changing trends of caesarean section, more liberalisation of indications like long marital life and elderly primi. No perinatal loss. A very few postoperative complications like blood transfusion and surgical site infections were seen.

\section{CONCLUSION}

Because of small family norm in the present days, obstetrician and family cannot afford to lose even one baby. Even low Apgar baby was also not accepted. With the advent of regular antenatal care, all foetal and maternal complications were picked up early. Good anaesthetic facilities made caesarean the safest mode of delivery for the mother and the baby.

\section{KEYWORDS}

Primi, Caesarean Section, Elective.

HOW TO CITE THIS ARTICLE: Jayanthi P, Ratna G. Analysis of indications and complications of elective caesarean section in primi at a tertiary care centre, Vijayawada, Andhra Pradesh, India. J. Evolution Med. Dent. Sci. 2017;6(94):6849-6853, D0I: $10.14260 /$ jemds/2017/1484

\section{BACKGROUND}

From 1970 to 2010, caesarean delivery rates were rising gradually and reached almost $30 \%$ in tertiary care centres. In some institutes even more caesarean section rates were demonstrated, because of high referrals. Most common indication was repeat caesarean section. If we can reduce the primary caesarean section rate automatically, we can reduce the total caesarean section rate. According to WHO, rate of caesarean section of $>15 \%$ indicate over-utilisation of procedure. $^{1}$

'Financial or Other Competing Interest': None.

Submission 23-11-2017, Peer Review 05-12-2017,

Acceptance 08-12-2017, Published 18-12-2017.

Corresponding Author:

Ganti Ratna,

C/o. G. Eswar, Suryarao Peta,

Dasarivari Street 29-28-73,

Vijayawada.

E-mail: gantiratna@gmail.com

DOI: $10.14260 /$ jemds/2017/1484

[WHO 1993] Many are questioning the optimal caesarean section rate by suggesting that lowering caesarean section rate may be dangerous. ${ }^{2}$ In Delhi, caesarean section rate in some tertiary hospitals ranges between $19 \%$ and $35 \% .{ }^{3}$ In our institution, caesarean section rate is around 35\%.

Why there are increasing rates of caesarean sections being reported. This is because in the present day obstetric practice, most of the caesarean sections were performed for foetal indications rather than maternal indications like big baby, foetal distress, breech, twins and meconium stained liquor. According to Mackenzie et al, the caesarean section rate for singleton breech has gradually raised from $27 \%$ to $86 \%$ and twin pregnancy from $13 \%$ to $47 \%{ }^{4}$ With the advent of good antenatal facilities, much more diagnosis of oligohydramnios were being identified. In a study of Pradip R and Gaikward et al, oligohydramnios of $<5$ AFI was associated with high caesarean section rate in view of foetal distress. ${ }^{5}$ Colour Doppler and electronic foetal heart rate monitoring has also contributed to little increase in the rate of caesarean section. Because the most common indication 
for caesarean section was repeat section. If we can reduce the primary caesarean, we can control the total caesarean section rate. High risk pregnant women do not show any variation wherever they deliver. The largest variation occurs in the low risk patients, especially nulliparous women with vertex presentation and with low risk factors. Hence, the present study aims at analysis of indications and complications of primary elective caesarean section. Study also focuses on the factors influencing the operative delivery in the first pregnancy.

\section{MATERIALS AND METHODS}

Present study was a prospective descriptive study conducted in the Government General Hospital, Vijayawada, a tertiary care centre in Andhra Pradesh from April 2017 to September 2017. Study material included the patients admitted in the Government General Hospital including antenatal ward and labour ward admissions.

\section{Inclusion Criteria}

1. All primi gravid women were subjected to caesarean section electively without giving any trial of labour.

2. Pregnant women were not in labour.

3. Pregnant women with previous abortions were also included; present pregnancy is the first pregnancy which crossed the period of viability.

4. Study include all antenatal and labour room admissions.

5. Referral cases were also taken up for present study.

\section{Exclusion Criteria}

1. Pre-eclampsia with complications were not included in the present study.

2. Placenta previa with bleeding were not included in the present study.

All cases recruited for study were analysed for indication of LSCS, gestational age at the time of surgery, maternal and perinatal outcome and complications of caesarean section. Attitude of the women towards caesarean section was noted. All patients were followed till discharge.

\section{RESULTS}

Results were tabulated and analysed.

\begin{tabular}{|c|c|c|}
\hline Total No. of LSCS & $\mathbf{1 9 2 9}(\mathbf{n = 1 9 2 9 )}$ & $\mathbf{1 0 0 \%}$ \\
\hline Repeat elective & 220 & $11.84 \%$ \\
\hline Repeat emergency & 690 & $35.70 \%$ \\
\hline Primary emergency & 809 & $41.93 \%$ \\
\hline Primary elective & 210 & $10.53 \%$ \\
\hline \multicolumn{2}{|c|}{ Table 1. Total Number of Caesarean Sections (April - } \\
September 2017) \\
\hline
\end{tabular}

Caesarean section rate in India is between $15 \%$ and $30 \%$. It is little high in teaching hospitals. In our hospital, caesarean section rate is $43 \%$. In present study, in 6 months period total number of deliveries were 4263. A total of 1929 number of caesarean sections were performed. The remaining 2334 were normal deliveries. $43 \%$ caesarean section rate was reported in the present study. It is higher than other studies. Saha et al from Kolkata reported 29\% caesarean section rate. 6 This is because of high dependence unit in our hospital and more number of referrals. Because of round the clock facilities for caesarean section, pregnant women who need caesarean section were referred directly to the health facility.

\begin{tabular}{|c|c|c|}
\hline Age & $\mathbf{n = 2 1 0}$ & Percentage \\
\hline Age $<$ 20 years & 21 & $10 \%$ \\
\hline 20 to 25 years & 143 & $68.09 \%$ \\
\hline 25 to 30 years & 29 & $13.8 \%$ \\
\hline 30 to 35 years & 12 & $5.7 \%$ \\
\hline$\bullet \quad 35$ years & 5 & $2.3 \%$ \\
\hline$\bullet \quad$ 40 years & 0 & 0 \\
\hline \multicolumn{2}{|c|}{ Table 2. Age Wise Distribution of Cases } \\
\hline
\end{tabular}

In the present study, $10 \%$ of patients were less than 20 years old. $68.09 \%$ of pregnant women were between 20 and 25 years. $13.8 \%$ of women were between 25 and 30 years. Age is an important factor in determining the route of delivery. More liberal decision will be resorted to if age is more than 30 years. In our study $12 \%$ of women were between 30 and 35 years, $5 \%$ of pregnant women were above 40 years of age (Table 2). Elderly primi are associated with more medical complications like diabetes, hypertension, obesity and dystocia dystrophia syndrome. Elderly primi gravida with long marital life was considered very precious pregnancy. Much more liberal decision was taken regarding conduct of delivery and caesarean section is the most favoured option.

\begin{tabular}{|c|c|c|}
\hline B/UB & Number & Percentage \\
\hline Booked & 115 & $54.76 \%$ \\
\hline Unbooked & 95 & $45.23 \%$ \\
\hline Table 3. Booking Status at Admission \\
\hline
\end{tabular}

\begin{tabular}{|c|c|c|}
\hline Admission to Delivery & Number & Percentage \\
\hline$<24$ hrs. & 46 & $21.90 \%$ \\
\hline 24 to 72 hrs. & 74 & $35.23 \%$ \\
\hline$>72$ hrs. & 52 & $24.76 \%$ \\
\hline$>5$ days & 23 & $10.95 \%$ \\
\hline 10 to 30 days & 12 & $5.71 \%$ \\
\hline$>30$ days & 3 & $1.4 \%$ \\
\hline \multicolumn{2}{|c|}{ Table 4. Admission Delivery Interval } \\
\hline
\end{tabular}

In present study $21.9 \%$ delivered in 24 hours, $35.23 \%$ in 72 hours, $10.95 \%$ in 5 days and $7.1 \%$ stayed in ward for longer time. Prolonged hospital stay was necessary in preeclampsia and gestational diabetes patients.

\begin{tabular}{|c|c|c|}
\hline Indication & Number & Percentage \\
\hline 1. Oligohydramnios & 59 & $29.1 \%$ \\
\hline 2. $\mathrm{PIH}$ & 25 & $11.9 \%$ \\
\hline 3. Breech & 39 & $19.17 \%$ \\
\hline 4. CPD & 20 & $9.5 \%$ \\
\hline 5. Short primi & 16 & $7.6 \%$ \\
\hline 6. Transverse lie & 5 & $2.3 \%$ \\
\hline 7. Doppler changes & 5 & $2.3 \%$ \\
\hline 8. Elderly primi & 5 & $2.3 \%$ \\
\hline 9. Twins & 5 & $2.3 \%$ \\
\hline 10. Previous abortions & 4 & $1.91 \%$ \\
\hline 11. GDM & 11 & $5.4 \%$ \\
\hline 12. Triplets & 1 & $0.4 \%$ \\
\hline 13. IUGR & 7 & $3.3 \%$ \\
\hline 14. Fibroid in LUS & 1 & $0.4 \%$ \\
\hline 15. Placenta previa & 1 & $0.4 \%$ \\
\hline 16. Contracted pelvis & 1 & $0.4 \%$ \\
\hline 17. Long marital life & 5 & $2.3 \%$ \\
\hline Total & 210 & $100 \%$ \\
\hline
\end{tabular}


In the present study, oligohydramnios has contributed to major proportion of caesarean sections. $29.1 \%$ of caesarean sections were due to less liquor. Next major contribution was by breech accounting to $18.5 \%$ of caesarean sections, cephalopelvic disproportion of $9.5 \%$ and short primi of $7.6 \%$ cases. One case of fibroid complicating pregnancy, one case of placenta previa and one case of contracted pelvis each. Some of the pregnant women had multiple risk factors like preeclampsia with oligohydramnios. But major determining factor was considered for selection into that particular category.

\begin{tabular}{|c|c|c|}
\hline Gestational Age & Number & Percentage \\
\hline$<28$ to 32 weeks & 1 & $0.4 \%$ \\
\hline $32-36$ weeks & 31 & $14.76 \%$ \\
\hline$>36$ weeks & 31 & $14.76 \%$ \\
\hline$>37$ weeks & 106 & $50.47 \%$ \\
\hline$>40$ weeks & 41 & $19.52 \%$ \\
\hline Table 6. Gestational Age at the Time of Caesarean Section \\
\hline
\end{tabular}

\begin{tabular}{|c|c|c|}
\hline Spinal & 208 & $99.04 \%$ \\
\hline General & 2 & $.06 \%$ \\
\hline \multicolumn{2}{|c|}{ Table 7. Type of Anaesthesia for Caesarean Section } \\
\hline
\end{tabular}

In present study, $50.47 \%$ of elective caesarean sections were performed after 37 weeks. $19.2 \%$ of caesarean sections were performed after 40 weeks of gestation. Why caesarean section was taken up after 40 weeks is because of referral cases in whom surgery is required, being referred after 40 weeks. Usually caesarean section will be planned electively after lung maturity, i.e. after 37 weeks of pregnancy. In present study (total 32 patients) $15.16 \%$ of pregnant women were delivered before 36 weeks. The reasons for posting early at less than 36 were severe oligohydramnios in $6.19 \%$, IUGR in $1.9 \%$ of patients, preeclampsia in $6.19 \%$ and Doppler abnormality in $0.95 \%$ of cases.

\begin{tabular}{|c|c|c|}
\hline Birth Weight & Number & Percentage \\
\hline Less than $2 \mathrm{~kg}$ & 23 & $10.9 \%$ \\
\hline 2 to $2.5 \mathrm{~kg}$ & 51 & $24.2 \%$ \\
\hline 2.5 to $3 \mathrm{~kg}$ & 53 & $25.2 \%$ \\
\hline 3 to $3.5 \mathrm{~kg}$ & 64 & $29.5 \%$ \\
\hline 3.5 to $4 \mathrm{~kg}$ & 8 & $3.8 \%$ \\
\hline$>4 \mathrm{~kg}$ & 11 & $5.2 \%$ \\
\hline \multicolumn{2}{|c|}{ Table 8. Birth Weight of Newborn } \\
\hline
\end{tabular}

In the present study $10.9 \%$ of babies weighed less than 2 $\mathrm{kg}, 24.2 \%$ weighed between 2 to $2.5 \mathrm{~kg}, 25.2 \%$ newborn weighed between 2.5 to $3 \mathrm{~kg}, 29.5 \%$ babies were born with birth weight between 3 and $3.5 \mathrm{~kg}$; $3.8 \%$ were between 3.5 to $4 \mathrm{~kg}$ and $5.2 \%$ of newborn weighed above $4 \mathrm{~kg}$. Most of the large babies were from pregnant women with gestational diabetes.

\begin{tabular}{|c|c|c|}
\hline Admissions & n= 20 & Percentage \\
\hline Low birth weight & 15 & $75 \%$ \\
\hline Low APGAR & 2 & $12 \%$ \\
\hline Observation > 4 kg & 3 & $13 \%$ \\
\hline \multicolumn{2}{|c|}{ Table 9. NICU Admissions } \\
\hline
\end{tabular}

Total 20 newborns were admitted in NICU. $75 \%$ of admissions were due to low birth weight. $12 \%$ of admissions were with low APGAR score. $13 \%$ of admissions were for observation in view of birth weight more than $4 \mathrm{~kg}$. All admitted new born babies were discharged safely.

\begin{tabular}{|c|c|c|}
\hline Complication & Number & Percentage \\
\hline Febrile morbidity & 27 & $12.8 \%$ \\
\hline Transfusions & 7 & $3.3 \%$ \\
\hline Surgical site infection & 24 & $11.4 \%$ \\
\hline Secondary suturing & 5 & $2.3 \%$ \\
\hline Post spinal headache & 1 & $0.4 \%$ \\
\hline \multicolumn{2}{|c|}{ Table 10. Postoperative Complications (n= 210) } \\
\hline
\end{tabular}

Very few postoperative complications were noted. Febrile morbidity in $12.8 \%$ of surgeries, $3.3 \%$ of patients needed intra-operative or post-operative blood transfusion. All patients were given antimicrobial prophylaxis with 1 gram of ceftriaxone 1 hour before surgery. In spite of antimicrobial prophylaxis, surgical site infection was seen in $11.4 \%$ of patients. Wound swab was sent for culture and sensitivity for all patients with surgical site infection and treated accordingly. All these patients have prolonged hospital stay. In $2.3 \%$ of patients, secondary suturing was done because of wound gaping. Only skin sutures were applied. Rectus sheath was intact (Table 10). Present study had only one case of post spinal headache, that is $0.4 \%$ only.

\section{DISCUSSION}

There are so many factors influencing the decision of caesarean section. These are not only medical but also social, economic and changing cultural factors. Late marriage, advanced age at first conception, preference to one or two children, increased cost of neonatal facilities and lack of paediatrician round the clock also influences the decision making.

Nowadays, maternal age is influencing the mode of delivery. In a study by Liu et al, approximately $15 \%$ increase in caesarean section rate was contributed by increase in maternal age. ${ }^{7}$ Elderly primi itself is becoming the indication for caesarean section. But in Andhra Pradesh, Vijayawada, most of our women got married early. So teenage pregnancy and its complications are more likely than late marriage. In our study $2.3 \%$ of cases were elderly primi, taken up for caesarean section.

In the present study, short primi of less than $140 \mathrm{~cm}$ were taken up for caesarean section. Liberal decision was taken for short statured women. It is almost equal to other studies. According to Rusliena et al 2011, short stature is associated with higher rates of CPD. ${ }^{8}$ In the present study, $7.6 \%$ of cases were operated because of short stature.

All primigravida with Breech presentation were taken up for caesarean section, unless they present with advanced cervical dilatation. $57.4 \%$ of caesarean section rate was reported by Asha Singh et al and 33.2\% vaginal deliveries in term Breech trial by Hannah et al. ${ }^{9}$

In the present study, more caesarean sections for breech were reported. This is because of non-acceptance of vaginal delivery after explaining the risk and complications.

CPD has contributed to $9.5 \%$ of caesarean sections. Most of the cases of CPD in present study were having multiple risk factors like preeclampsia and gestational diabetes, hence trial of labour was not attempted.

$28.1 \%$ of caesarean sections in present study were done because of oligohydramnios. It is on par with other studies. 
Other indications for caesarean section were elderly primi, long marital life, Doppler changes, twins and one case of placenta previa.

No caesarean section was performed on maternal request. Patient's demand for caesarean section has complicated this burning issue. In UK, caesarean on demand was the third most common indication for performing caesarean sections. ${ }^{10}$ Fear of pain, fear of injury to perineum and suspected future sexual dysfunction are some of the factors responsible for caesarean section on demand. In India, most of the people believe in astrology and they want their baby to be born in that particular auspicious time only. If the obstetrician starts considering their demand, naturally caesarean sections number will go up. This was shown in the study of Kabra et al.11 Present study showed that teaching institutes cannot take up caesarean section on demand, though some liberalisation was observed. NICE guidelines say that caesarean section is not available on demand unless clinically indicated (BMJ 2013; 347; 4649). In the present study, no caesarean was done on maternal request.

All caesarean sections except one were performed under spinal anaesthesia. No major intraoperative problems were reported. One case of mild post spinal headache was reported, which was treated with bed rest and IV fluids. No perinatal loss in present study. $57.4 \%$ of babies weighed between 2.5 and $3.5 \mathrm{kgs}$. Total 20 newborns were admitted in NICU (Table 8, 9).

Caesarean section is a major surgery and associated with its own complications, as in any other surgery either intra- or postoperative. Intraoperative complications include difficult delivery of baby, injury to bladder and bowel, extension of incision, extensions of tears into broad ligament with traumatic postpartum haemorrhage. Postoperative complications include postoperative pain, postpartum haemorrhage, febrile morbidity, sepsis, surgical site infections, wound gaping and postoperative flimsy adhesions giving rise to subacute intestinal obstruction. Sometimes, obese postoperative patients may develop postoperative thromboembolism. The risk of thromboembolism is more in pregnancy with obesity, gestational diabetes and preeclampsia, especially in postoperative period. 12 Postoperative wound infection is common in obese women, particularly the serious sometimes fatal problem of necrotising fasciitis. ${ }^{13}$ In the present study $12.8 \%$ showed febrile morbidity, $11.4 \%$ surgical site infection, $2.3 \%$ secondary suturing (skin only) and 3.3\% women were given blood transfusion (Table 10).

This is almost equal to the study of Shrestha et al, where they quoted $12.6 \%$ of surgical site infections in patients of postoperative caesarean section. ${ }^{14}$ All surgical site infections were cured by daily dressings and antibiotic coverage after culture and sensitivity of wound swab. But there is prolongation of hospital stay by an average of 5 days. Secondary suturing after control of infection was done, patients were discharged and requested to come for suture removal after 15 days. Present study had only $0.4 \%$ of patients with post spinal headache. Other studies showed higher incidence. According to Parthasarathi et al, the incidence of post dural headache was $9.5 \%$ in all surgeries. ${ }^{15}$ No maternal or perinatal loss in the present study, thus making elective caesarean section a safer option if necessary.

\section{CONCLUSION}

After analysing the primary caesarean sections performed without any trial in first pregnancy reaching viability, that is 28 weeks the following findings were identified. Oligohydramnios, PIH and malpresentations contributed to majority of caesarean sections.

Liberalisation of primary elective caesarean section in view of changing demands from society. Fear of birth asphyxia, cost of neonatal care and non-availability of painless labour were important contributory factors. Changing age group and medical disorders complicating pregnancy were the major determinants in decision making nowadays. Good surgical and anaesthetic facilities made caesarean section a safe and first option for saving lives of mother and baby.

\section{REFERENCES}

[1] Appropriate technology for birth. Lancet 1985;2(8452)436-7.

[2] Anderson GM. Making sense of raising caesarean section rates. BMJ 2004;329(7468):696-7.

[3] Mukherjee SN. Rising cesarean section rate. J Obstet Gynaecol India 2006;56(4):298-300.

[4] Mackenzie IZ, Cooke I, Annan B. Indications for caesarean section in a consultant obstetric unit over decades. J Obstet Gynaecol 2003;23(3):233-8.

[5] Pradeep R, Gaikward D. Oligohydramnios and adverse perinatal outcome. IJROG 2016;2320:1699-770.

[6] Saha S, Saha S Das R, et al. A paradigm shift to check the increasing trend of caesarean delivery is the need of hour: but how? J Obstet Gynaecol India 2012;62(4)395-7.

[7] Liu S, Rusen ID. Joseph KS, et al. Recent trends in caesarean delivery rates and indications for caesarean delivery in Canada. J Obstet Gynaecol Can 2004;26(8)735-42.

[8] Toh-Adam R, Srisupundit K, Tongsong T. Short stature as an independent risk factor for cephalopelvic disproportion in a country of relatively small-sized mothers. Arch Gynaecol Obstet 2012;285(6):1513-6.

[9] Hannah ME, Hannah WJ, Hewson SA, et al. Planned caesarean section versus planned vaginal birth for breech presentation at term: a randomized multicentric trial. Term Breech Trial Collaborative Group. Lancet 2000;356(9239):1357-83.

[10] Atiba EO, Adeghe AJ, Murphy PJ, et al. Patients expectations and caesarean section rates. Lancet 1993;341(8839):246.

[11] Kabra SG, Narayanan R, Chaturvedi M, et al. What is happening to caesarean section rates? Lancet 1994;343(8890):179-80.

[12] Cantwell R, Clutton-Brock T, Cooper G, et al. Saving mothers' lives: reviewing maternal deaths to make motherhood safer: 2006-2008. The eighth report of the confidential enquiries into maternal deaths in the United Kingdom. Br J Obstet Gynaecol 2011;118 Suppl 1:1-203.

[13] Gallup DG, Freedman MA, Meguiar RV, et al. Necrotising fasciitis in gynecological and obstetric patients: a surgical emergency. Am J Obstet Gynecol 2002;187(2):305-10. 


\section{Jemds.com}

[14] Shrestha S, Shrestha R, Shrestha B, et al. Incidence and risk for surgical site infection following caesarean section at Dhulikhel Hospital. Khatmandu Univ Med J 2014;12(2):113-6.

\section{Original Research Article}

[15] Parthasarathi S, Sivashanmugam T. Incidence of postdural puncture headache in Indian population: a need for relook. Asian J Pharma Clin Res 2016;9(2):230-3. 